\title{
Investigating the Performance of EDM Process using Tool Rotation Methodology for Machining INCOLOY 800HT
}

\author{
Sourabh Sinha ${ }^{* 1}$, Raj Ballav ${ }^{2}$, Amaresh Kumar ${ }^{3}$ \\ Department of Manufacturing Engineering, \\ National Institute of Technology, Jamshedpur, India - 831014 \\ ${ }^{1}$ sourabhmilan@gmail.com \\ ${ }^{2}$ rballav.prod@nitjsr.ac.in \\ 33akumar.prod@nitjsr.ac.in
}

\begin{abstract}
Electrical discharge machining (EDM) being one of the most earliest and accepted nonconventional machining process is used in achieving intricate shapes in difficult to machine materials. Material removal rate (MRR) is one of the machining performances measures which are always discussed while adopting any machining process. In this paper tool rotation methodology has been adopted to observe the effect on MRR while machining INCOLOY 800HT using EDM. The experimental results show that tool rotation improves the MRR of the machined material.
\end{abstract}

Keyword-Electric discharge machining (EDM), INCOLOY 800HT, Response surface methodology (RSM), Box-Behnken, Material removal rate (MRR)

\section{INTRODUCTION}

To achieve precise complex shapes manufacturers nowadays uses non-conventional machining processes compared to conventional processes. Benefit of using non-conventional processes over conventional processes ranges from shorter span of machining time to machining of hard materials with complex shapes [1]. EDM uses thermal energy to machine materials which are hard to machine and electrically conductive in nature. EDMs are used to manufacture die, moulds, and automotive, surgical and aerospace components [2]. There is no direct contact between the workpiece and the electrode in EDM, hence eliminating mechanical stresses chatter and vibration problems during machining [3]. In EDM metal is removed from the work piece in the form of erosion as a result of recurring spark discharge taking place between tool and the work piece through the dielectric medium [4].

INCOLOY 800HT (registered trademark of Special Metals, USA) is a Nickel based super alloy having characteristics of high creep rupture strength and great corrosion resistance in acidic and sulphur containing atmosphere. Nickel based super alloys are generally used in petrochemical industries, electric power generators, gas turbines, chemical processing plants requires high temperature and high pressure resistive materials [5]. Having such extraordinary properties, INCOLOY $800 \mathrm{HT}$ are used in various industries such as, chemical and petrochemical processing industries for heat exchangers, super-heater and re-heater in power plants, heat treating equipments, and ethylene furnace quench boilers. According to the study presented by Nickel Development Institute and Special Metals Corporation, USA, INCOLOY 800HT is a difficult to machine alloy with the use of conventional machining processes. Therefore, non-conventional machining process as EDM is considered for the present study.

The main deficiency of EDM process is its low MRR. In the recent years researchers have adopted different methodologies to overcome this drawback. Tool rotation methodology is a good alternative to enhance the performance of the basic EDM process. The present work is aimed at increasing the MRR of EDM using tool rotation methodology.

\section{EXPERIMENTATION}

The experimental set-up used in experimentation for the present study is shown in Fig. 1. Experiments have been performed on AGIE 250C die-sinking EDM machine manufactured in Switzerland. The experiments were designed using Box-Behnken design of experiments as it avoids corner points and star points [6]. Box-Behnken design of experiment as per response surface methodology helps in optimizing a process using a small number of experimental runs. The design was generated and analysed using the MINITAB statistical software. INCOLOY 800HT (Dimensions: 30mm x 30mm x 10mm, and Composition: $\mathrm{Ni}=30.0-35.0 \%, \mathrm{Cr}=19.0-23.0 \%$, $\mathrm{Fe}=39.5 \%$ min., $\mathrm{C}=0.06-0.10 \%, \mathrm{Al}=0.25-0.60 \%, \mathrm{Ti}=0.25-0.60 \%, \mathrm{Al}+\mathrm{Ti}=0.85-1.20 \%$ ) is selected as work material because of its high creep rupture strength, high temperature strength, and high corrosive resistant strength. The electrode material consumed for the present work is copper electrode of $15 \mathrm{~mm}$ diameter which is 99.99\% Cu. 


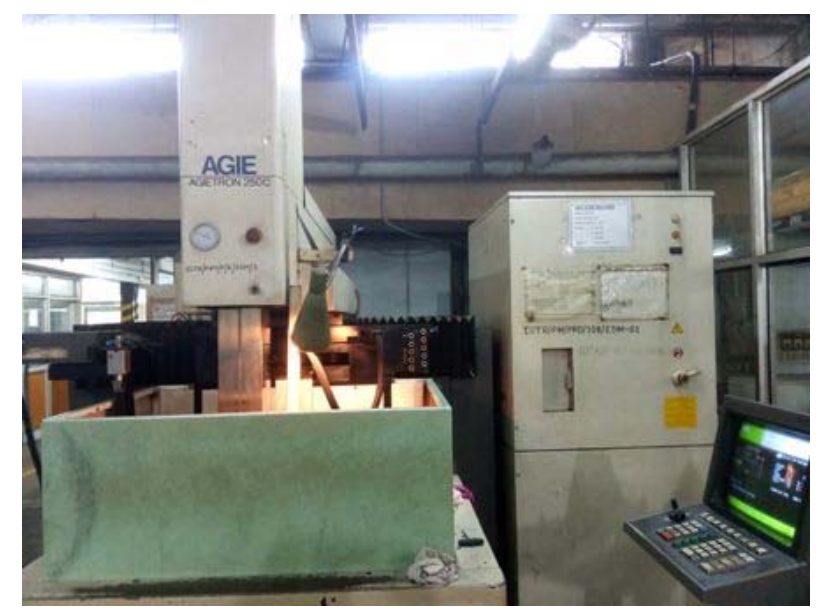

Fig.1. Die-Sinking EDM machine for experimentation

Machining conditions considered during experimentation are listed in TABLE 1and TABLE 2 shows the various input parameters at three different levels.

TABLE 1. Machining Conditions

\begin{tabular}{|l|l|}
\hline Work piece & INCOLOY 800HT \\
\hline Tool electrode & Copper \\
\hline Polarity & Positive \\
\hline Dielectric & EDM oil SE 180 \\
\hline Inter-electrode gap & $0.08 \mathrm{~mm}$ \\
\hline Method of flushing & Side flushing \\
\hline Tool Rotation Speed & $30 \mathrm{rpm}$ \\
\hline
\end{tabular}

TABLE 2. Coded and Real Levels of Independent Variables

\begin{tabular}{|l|c|c|c|c|}
\hline Parameters & Symbol & \multicolumn{3}{|c|}{ Levels } \\
\hline Coded values & & $\mathbf{- 1}$ & $\mathbf{0}$ & $+\mathbf{1}$ \\
\hline Current $(\mathrm{A})$ & A & 5 & 10 & 15 \\
\hline Voltage $(v)$ & B & 2 & 4 & 6 \\
\hline Pulse on-time $(\mu \mathrm{s})$ & C & 10 & 18 & 26 \\
\hline
\end{tabular}

Total 30 numbers of experiments were performed, 15 each for stationary and rotary tool conditions. TABLE 3 and TABLE 4, shows the experimentally obtained values for material removal rate for stationary and rotational tool EDM process.

TABLE 3. MRR for Stationary Tool EDM

\begin{tabular}{|c|c|c|c|c|}
\hline SI. No. & Current (A) & Voltage (v) & Pulse on-time ( $\mathbf{\mu s})$ & MRR $\mathbf{( m m}^{\mathbf{3}} \mathbf{m i n}$.) \\
\hline 1 & 10 & 2 & 26 & 6.423 \\
\hline 2 & 5 & 6 & 18 & 0.252 \\
\hline 3 & 15 & 4 & 26 & 72.141 \\
\hline 4 & 5 & 4 & 10 & 0.063 \\
\hline 5 & 10 & 4 & 18 & 25.063 \\
\hline 6 & 10 & 4 & 18 & 25.069 \\
\hline 7 & 5 & 4 & 26 & 0.126 \\
\hline 8 & 15 & 6 & 18 & 74.988 \\
\hline 9 & 10 & 6 & 26 & 7.305 \\
\hline 10 & 10 & 6 & 10 & 7.935 \\
\hline 11 & 5 & 2 & 18 & 0.126 \\
\hline 12 & 10 & 4 & 18 & 25.059 \\
\hline 13 & 15 & 4 & 10 & 47.308 \\
\hline 14 & 10 & 2 & 10 & 1.637 \\
\hline 15 & 15 & 2 & 18 & 81.360 \\
\hline
\end{tabular}


TABLE 4. MRR for Rotating Tool EDM

\begin{tabular}{|c|c|c|c|c|}
\hline SI. No. & Current (A) & Voltage (v) & Pulse on-time ( $\mu \mathrm{s})$ & $\operatorname{MRR}\left(\mathrm{mm}^{3} / \mathrm{min}.\right)$ \\
\hline 1 & 10 & 2 & 26 & 11.688 \\
\hline 2 & 5 & 6 & 18 & 0.346 \\
\hline 3 & 15 & 4 & 26 & 86.272 \\
\hline 4 & 5 & 4 & 10 & 0.076 \\
\hline 5 & 10 & 4 & 18 & 26.717 \\
\hline 6 & 10 & 4 & 18 & 26.715 \\
\hline 7 & 5 & 4 & 26 & 0.152 \\
\hline 8 & 15 & 6 & 18 & 84.635 \\
\hline 9 & 10 & 6 & 26 & 8.165 \\
\hline 10 & 10 & 6 & 10 & 8.472 \\
\hline 11 & 5 & 2 & 18 & 0.169 \\
\hline 12 & 10 & 4 & 18 & 26.716 \\
\hline 13 & 15 & 4 & 10 & 59.824 \\
\hline 14 & 10 & 2 & 10 & 2.267 \\
\hline 15 & 15 & 2 & 18 & 87.705 \\
\hline
\end{tabular}

MRR Measurement Technique:

Material removal rate (MRR) is calculated by determining the volume of material removed from the work piece during each experimental run [7]. Formula to calculate MRR is given by equation 1 .

$$
\operatorname{MRR}\left(\mathrm{mm}^{3} / \mathrm{min}\right)=\frac{\text { Volume of material removed from workpiece }}{\text { Density } \times \text { time }}
$$

\section{III.DATA ANALYSIS AND DISCUSSION}

As per the experimental data obtained, it is clear that the MRR increases with the use of electrode rotation while machining the work piece with the help of EDM process. Rotation of the electrode helps in solving the flushing difficulty which arises during machining hole of small diameter with EDM process [8]. Flushing is improved by pumping effect of the dielectric through the gap. This not only increases the MRR but also produces hole of better quality compared to stationary electrode [9]. For better understanding of the experimental results, a comparative graph between MRR for stationary tool EDM and MRR for rotational tool EDM is plotted against the standard order of the experiment. From Fig. 2, it is seen that MRR during rotary EDM process is increased as compared to stationary process.

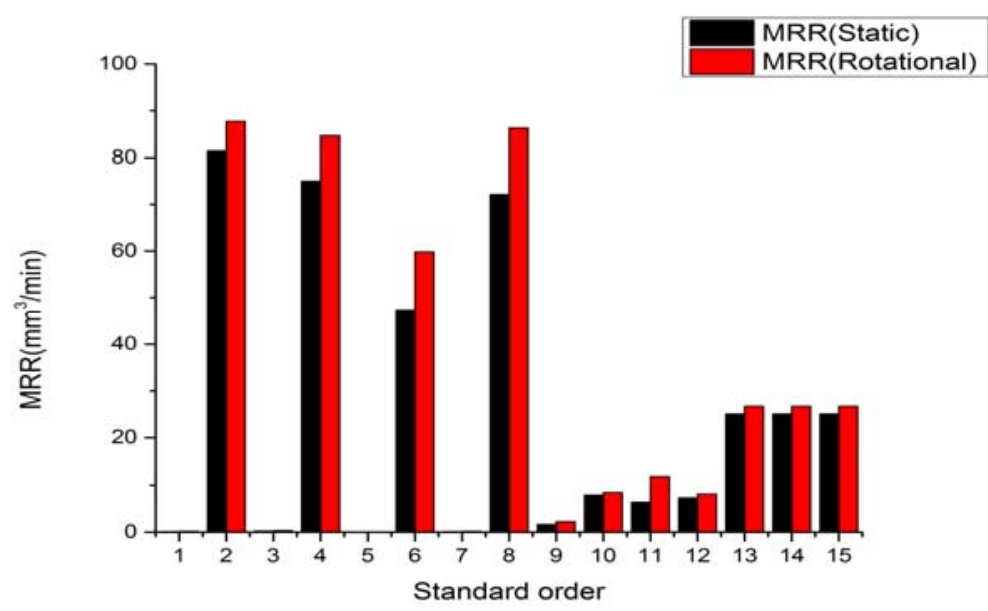

Fig.2. MRR vs Standard Order

Better MRR is obtained with the electrode rotation where molten material is frequently cleared from the melt pool. As due to better flushing during electrode rotation technique, there is no left over molten material between the work piece and the tool, spark intensity increases, which in turn causes more surrounding material to melt. Hence, material in the vicinity of the spark gets melted and frequent flushing by the flow of the dielectric helps in improved MRR. 


\section{A. Recast Layer Analysis for Stationary EDM}

Recast layer Analysis for INCOLOY 800HT has been carried out using a scanning electron microscope. The images observed by the SEM process suggest that the recast layer thickness is not uniform. The obtained images are at a magnification level of 1000 times the original size. From the Fig. 3 it can be seen a lot more microcracks as compared to the rotary tool.

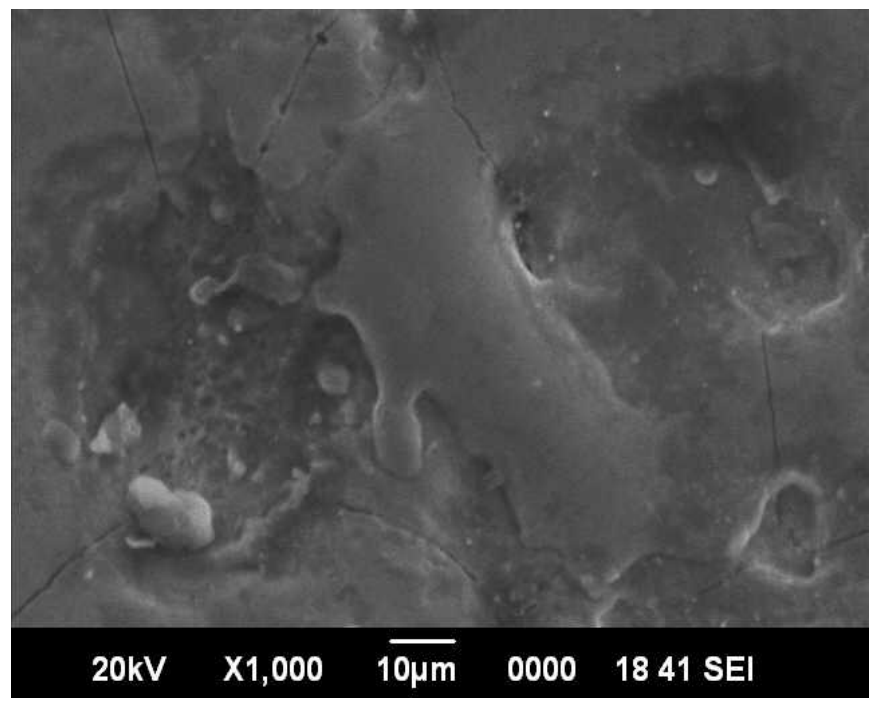

Fig.3. SEM Image of INCOLOY 800HT Using Stationary EDM Process

\section{B. Recast Layer Analysis for Rotary EDM}

From the Fig. 4 it is observed that there are less micro-crack on the work piece as compared to stationary EDM process. This is due to the fact that flushing system is improved in the rotary process carrying away the debris from the work piece with the dielectric flow, whereas, in the case of Stationary EDM debris remains on the surface and after hardening forms a recast layer with several micro-cracks on the work piece surface.

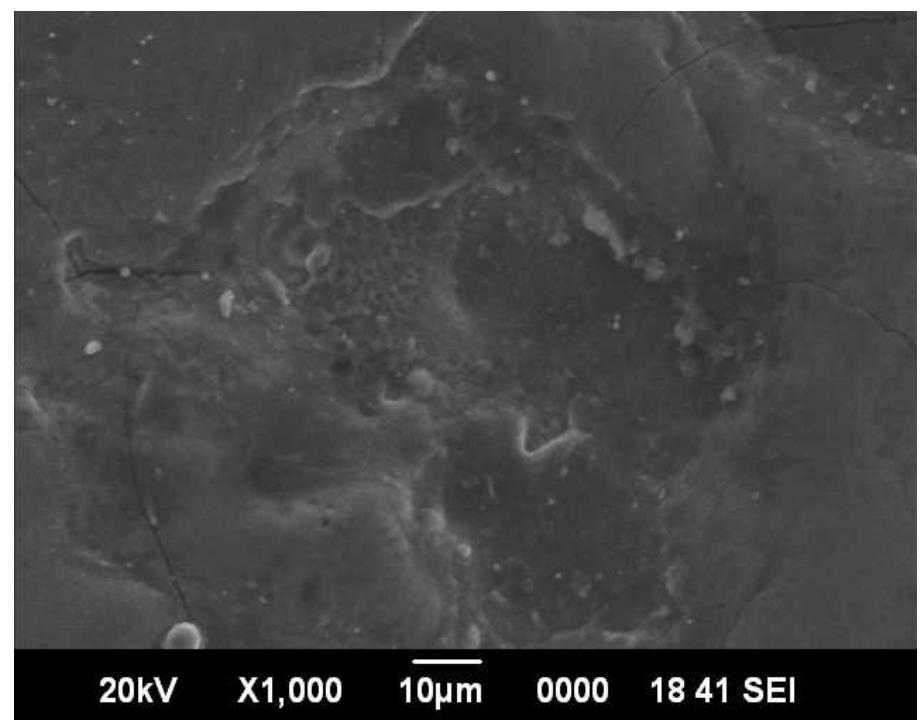

Fig.4. SEM Image of INCOLOY 800HT Using Rotary EDM Process

\section{CONCLUSION}

In this research paper an attempt has been made to experimentally analyze the effect of tool rotation process over stationary tool process while machining INCOLOY 800HT using EDM. From the obtained results it is concluded that rotary tool EDM gives a better MRR with less micro-cracks on the machined surface. This happens due to better flushing of the debris which results in less molten material deposition on the work piece surface. As there is lesser molten material deposition on the work piece surface, the hardened layer after solidification is almost half of that in stationary tool EDM, hence minimizing the chances of micro-cracks to appear on the work piece surface. 


\section{ACKNOWLEDGMENT}

The authors would like to sincerely thanks for the support of Department of Manufacturing Engineering, National Institute of Technology, Jamshedpur, India and IDTR, Jamshedpur, India for providing experimental set-up for this research work.

\section{REFERENCES}

[1] Chinmaya P Mohanty, Siba Shankar Mahapatra and Manas ranjan Singh, "An Experimental Investigation of Machinability of Inconel 718 in Electrical Discharge Machining,” Procedia Materials Science, vol. 6, pp. 605-611, 2014.

[2] Ho, K.H., and Newman, S.T., "State of the Art Electrical Discharge Machining (EDM)," International Journal of Machine Tools \& Manufacture, vol. 43, pp.1287-1300, 2003.

[3] Ahmet Hascalik and Ulas Caydas, “Electrical Discharge Machining of Titanium alloy (Ti-6Al-4V),” Applied Surface Science, vol. 253, pp. 9007-9016, 2007.

[4] Mohd. Junaid Mir, Khalid Sheikh, Balbir Singh and Navdeep Malhotra, "Modeling and analysis of machining parameters for surface roughness in powder mixed EDM using RSM approach,” International Journal of Engineering, Science and Technology, vol. 4, no. 3, pp. 45-52, 2012.

[5] V.Muthukumar, N.Rajesh, R.Venkatasamy, A.Sureshbabu, and N.Senthilkumar, "Mathematical Modelling for Radial Overcut on Electrical Discharge Machining of Incoloy 800 by Response Surface Methodology”, Procedia Materials Science, vol. 6, pp. 1674-1682, 2014.

[6] K. Palainkumar and J. Paulo Davim, "Electrical discharge machining study on machining characteristics of WC/Co composites", Woodhead Publishing Limited, vol. 5, pp. 135-168, 2013.

[7] V. Srivastva and P.M. Pandey, "Effect of process parameters of EDM process with ultrasonic assisted cryogenically cooled electrode," Journal of Manufacturing Process, vol. 14, pp. 393-402, 2012.

[8] S.K. Choudhary and R.S. Jadoun, "Current advanced research development of electric discharge machining (EDM) : A Review," International Journal of Research in Advent Technology, vol. 2, no. 3, 2014.

[9] T. Sato, T. Mizutani, K. Yonemouchi and K. Kawata, "The development of an electro discharge machine for micro hole boring," Precision Engineering, vol. 8, pp. 163-168, 1986.

\section{AUTHOR PROFILE}

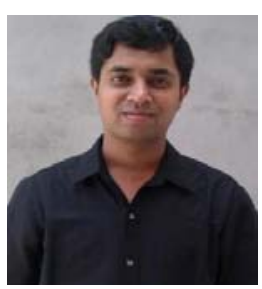

SOURABH SINHA Research Scholar in Department of Manufacturing Engineering, National Institute of Technology, Jamshedpur, India-831014. Did his B.Tech in Mechanical Engineering from Biju Patnaik University of Technology, Odisha in 2007 and completed M.Tech in CAAD from Birla Institute of Technology, Ranchi in 2011. His area of interest includes Machining, Manufacturing, CAD/CAM.

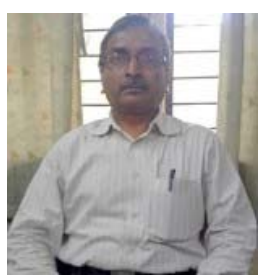

Dr. RAJ BALLAV Currently working as Associate Professor in the Department of Manufacturing Engineering, National Institute of Technology, Jamshedpur. Has done his $\mathrm{PhD}$ from Ranchi University in 2008. His area of interest includes CAD/CAM, Rapid Prototyping, and Production. Has published number of national and international articles in indexed journals.

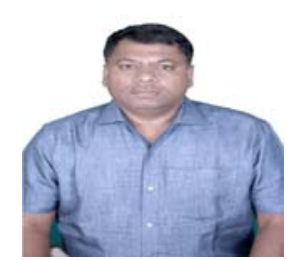

Dr. AMARESH KUMAR He did his B.E in Mechanical Engineering from Mysore university in 1993, M.Tech in 1996 from NIT Jamshedpur and PhD in 2006 from Jadavpur University , KOLKATA. He joined NIT JAMSHEDPUR on 22.02.1997 as Lecturer and presently he is Associate Professor \& HOD of the Department of Manufacturing Engineering and also Associate Dean (UG). He has guided 3 numbers of PhD Research Scholar and 06 numbers of M.Tech scholars. He has published more than 20 papers in International journals and more then 16 papers in National / International Conferences. His area of Work includes CAD/ CAM, Lean Manufacturing, Advance Machining. 